\title{
Article \\ Short-Term Impact of Video-Assisted Thoracoscopic Surgery on Lung Function, Physical Function, and Quality of Life
}

\author{
Yoshiteru Akezaki ${ }^{1}{ }^{\circledR}$, Eiji Nakata ${ }^{2, *}{ }^{\circledR}$, Ritsuko Tominaga ${ }^{3}$, Orie Iwata ${ }^{4}$, Juichi Kawakami ${ }^{5}$, Tetsuya Tsuji ${ }^{6}$, \\ Tsuyoshi Ueno ${ }^{7}$, Motohiro Yamashita ${ }^{7}$ and Shinsuke Sugihara ${ }^{3}$ \\ 1 Division of Physical Therapy, Kochi Professional University of Rehabilitation, Kochi 781-1102, Japan; \\ akezakiteru@yahoo.co.jp \\ 2 Department of Orthopaedic Surgery, Okayama University Hospital, Okayama 700-8558, Japan \\ 3 Department of Rehabilitation Medicine, National Hospital Organization Shikoku Cancer Center, \\ Ehime 791-0280, Japan; tominaga.ritsuko.fk@mail.hosp.go.jp (R.T.); \\ sugihara.shinsuke.rk@mail.hosp.go.jp (S.S.) \\ 4 Department of Rehabilitation Medicine, National Hospital Organization Tokushima Hospital, \\ Tokushima 776-8585, Japan; iwata.orie.jv@mail.hosp.go.jp \\ 5 Department of Rehabilitation Medicine, Shiga Prefectural Rehabilitation Center, Shiga 524-0022, Japan; \\ juichi-k@venus.dti.ne.jp \\ 6 Department of Rehabilitation Medicine, Keio University School of Medicine, Tokyo 160-8582, Japan; \\ cxa01423@nifty.com \\ 7 Department of Thoracic Surgery, National Hospital Organization Shikoku Cancer Center, \\ Ehime 791-0280, Japan; ueno.tsuyoshi.qz@mail.hosp.go.jp (T.U.); \\ yamashita.motohiro.tr@mail.hosp.go.jp (M.Y.) \\ * Correspondence: eijinakata8522@yahoo.co.jp
}

Citation: Akezaki, Y.; Nakata, E.; Tominaga, R.; Iwata, O.; Kawakami, J.; Tsuji, T.; Ueno, T.; Yamashita, M.; Sugihara, S. Short-Term Impact of Video-Assisted Thoracoscopic Surgery on Lung Function, Physical Function, and Quality of Life. Healthcare 2021, 9, 136. https:// doi.org/10.3390/healthcare9020136

Academic Editor: Parisi Attilio Received: 17 December 2020

Accepted: 23 January 2021

Published: 1 February 2021

Publisher's Note: MDPI stays neutral with regard to jurisdictional claims in published maps and institutional affiliations.

Copyright: (c) 2021 by the authors. Licensee MDPI, Basel, Switzerland. This article is an open access article distributed under the terms and conditions of the Creative Commons Attribution (CC BY) license (https:// creativecommons.org/licenses/by/ $4.0 /)$.

\begin{abstract}
Background: Video-assisted thoracoscopic surgery (VATS) has been increasingly used as an approach for lung lobectomy. However, the recovery of respiratory and physical function may be insufficient at discharge because the average length of hospital stay is decreasing after surgery. In this study, we investigated the changes in physical function, lung function, and quality of life (QOL) of lung cancer patients after VATS, and factors for QOL were also evaluated. Methods: The subjects of this study were 41 consecutive patients who underwent video-assisted lung lobectomy for lung cancer. Rehabilitation was performed both before and after surgery. Lung function testing, physical function testing (timed up and go test (TUG) and the 30-s chair-stand test (CS-30)), and QOL (EORTC QLQC30) were measured before and 1 week after surgery. Results: Postoperative VC recovered to $76.3 \%$ $\pm 15.6 \% 1$ week after surgery. TUG, CS-30, and QOL were significantly worse after surgery $(p<0.05)$. Lung function and physical function were found to affect QOL. Postoperative complications included pneumonia in 1 patient. There were no patients who discontinued rehabilitation. Conclusion: Our rehabilitation program was safe and useful for patients after VATS.
\end{abstract}

Keywords: lung cancer; surgery; physical function; lung function; quality of life

\section{Introduction}

Lung cancer is the most prevalent cancer diagnosed worldwide and is associated with the highest mortality [1,2]. Modern surgical treatment includes both minimally invasive surgery, e.g., video-assisted thoracoscopic surgery (VATS) and open surgery, such as thoracotomy. VATS has been increasingly used as an approach for lung lobectomy. The reported benefits of this technique when compared with open procedures include less postoperative pain [3,4], reduced length of hospital stay and loss of lung function [5], and better postoperative quality of life (QOL) [3]. Regarding rehabilitation for VATS patients, enhanced recovery program including rehabilitation has been shown to have no effect on cardiopulmonary complications, 30- and 90-day mortality, length of stay, and readmissions [6]. On the other hand, other studies have shown that most of VATS 
lobectomy patients demonstrated conditions potentially amenable to rehabilitation [7]. Therefore, it has been reported that all patients need to receive routine postoperative rehabilitation evaluations to identify problems early and correctly [7].

After VATS and thoracotomy, it takes 3-6 months for patients to recover more than $80 \%$ of vital capacity (VC) [8]. Regarding physical function, postoperative patients are prone to a decline in physical function due to bed rest and immobility following surgery. The recovery of respiratory and physical function may be insufficient at discharge compared to the preoperative level because the length of stay is shorter in lung cancer patients following VATS than after thoracotomy. This has an effect on the postoperative quality of life (QOL) of these patients. However, there are no studies of the changes of physical abilities and QOL from before to a short time after VATS. Clarifying the recovery of physical function and QOL at discharge is considered useful for medical staff to give activities of daily living (ADL) guidance and plan exercise for patients.

In this study, we investigated the changes in physical function, lung function, and QOL of lung cancer patients after VATS, and factors for QOL were also evaluated.

\section{Methods}

\subsection{Study Design}

This was a retrospective, observational study of lung and physical function and QOL in lung cancer survivors before and one week after VATS.

\subsection{Patients and Methods}

Among 91 patients who had undergone video-assisted lung lobectomy for lung cancer, 41 whose measurements were available from before and after surgery were included (Figure 1). The exclusion criteria were decreased cognitive function.

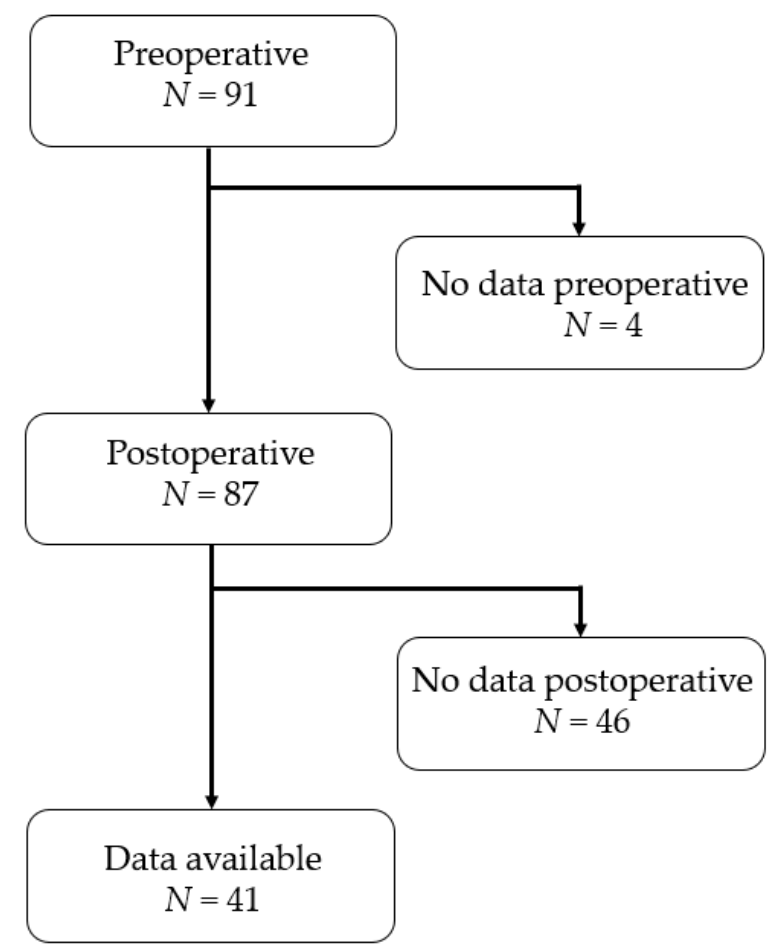

Figure 1. Flowchart of the study.

Lung function testing, physical function (timed up and go test (TUG) [9] and 30-s chair-stand test (CS-30) [10]), QOL (EORTC QLQ-C30) [11], postoperative pulmonary complications, and the day of starting walking after surgery were investigated. Measurements were performed before and 1 week after surgery. 


\subsection{Video-Assisted Thoracoscopic Surgery}

Four surgeons certified with Japanese association of respiratory surgery performed these VATS operations. Each surgeon had experience of more than 60 cases per year for more than 3 years. Surgeons performed VATS via a small $3-5 \mathrm{~cm}$ incision in the fourth or fifth intercostal space and 2 or 3 ports. Surgeons operated under complete monitor vision.

\subsection{Rehabilitation Program}

The preoperative program consisted of muscle-strengthening exercises including squatting and calf raise exercises, stretching including the upper limb, lower limb, and trunk, abdominal respiration, guidance in airway clearance including cough techniques, and respiratory muscle training with incentive spirometry (Coach ${ }^{\circledR}$, Smiths Medical Inc., Minneapolis, MN, USA), walking (more than $20 \mathrm{~min}$ per day), and aerobic exercise (15 to 30 min per day).

On postoperative day (POD) 1, guidance in airway clearance, abdominal respiration, sitting, standing, and standing still were started. On POD 2, walking was started. On POD 3 , aerobic exercise was started. On POD 4, stair climbing and descending were performed, and physical activities were increased depending on the patient's physical condition. The postoperative rehabilitation was $20-40 \mathrm{~min}$ per day. The timing of mobilization changed according to the physical status of the patient for a few days.

The preoperative and postoperative exercise intensity was set to the Borg CategoryRatio scale (Borg CR-10) of 3-5 points. The preoperative and postoperative rehabilitation was given under the guidance of a physiotherapist.

Regarding the criteria at discharge, the doctor judged if the patients were following an uneventful postoperative course from chest $\mathrm{X}$-ray, blood data, and the physical condition and careful examination of the risk of developing postoperative complications.

\subsection{Lung Function}

Forced vital capacity (FVC), \%FVC (FVC/predicted), forced expiratory volume in $1 \mathrm{~s}$ (FEV1), FEV1\% (FEV1/FVC), \%FEV1 (FEV1 \% predicted) were evaluated with the patients seated using a spirometer (Spiro Shift sp-470, Fukuda Denshi, Tokyo, Japan). Predicted FVC was calculated using the equation developed by the Japanese Respiratory Society [12].

The predicted postoperative VC was evaluated as follows: predicted postoperative VC = preoperative $\mathrm{VC} \times$ (residual segment number/total segment number) [13]. The recovery rate of postoperative VC is the ratio of postoperative VC to predicted postoperative VC.

\subsection{Physical Function}

The TUG [9] was evaluated twice at an interval of $1 \mathrm{~min}$, with the fastest values adopted as the representative values. The time required to stand up from a chair when sitting, circle around a landmark set $3 \mathrm{~m}$ ahead, and sit back down on the chair as fast as possible was evaluated. The starting point for measurement was the time when the back of the patient left the backrest of the chair, with the end measurement point being when the patient sat back down in the chair.

Lower extremity muscle endurance was evaluated using the CS-30 [10]. The chairstand test was administered using a seat height of $40 \mathrm{~cm}$. The patients were encouraged to stand up from a chair as many times as possible without stopping, keeping the arms folded across the chest. At the signal "go", the participant rose to a full stand (body erect and straight) and then returned back to the initial seated position. Only full standing positions were counted. The analysis used the number of repetitions performed with the arms folded across the chest.

\subsection{Health-Related Quality of Life}

Cancer-specific health-related QOL was assessed by the EORTC QOL Questionnaire C30 [11]. The questionnaire incorporated five functional scales (physical, role, cognitive, emotional, and social functions), three symptom scales (fatigue, pain, nausea, and vom- 
iting), global health status, and a number of single items assessing additional symptoms (dyspnea, loss of appetite, insomnia, constipation, and diarrhea) and the perceived financial impact of the disease. All scores resulted in a value between 0 and 100; high scores on functional and global QOL imply a high level of function, while a higher score on the symptom scales indicates greater problems [14-16].

\subsection{Statistical Analysis}

For lung function, physical function, and QOL, pre- and postoperative comparisons were analysed using paired $t$-tests and Wilcoxon signed-rank tests. To assess the factors affecting QOL after surgery, stepwise multiple regression analyses were constructed using the items of QLQ-C30 as independent variables and the data of age, presence or absence of chronic obstructive pulmonary disease (COPD), TUG after surgery, CS-30 after surgery, recovery rate of postoperative $\mathrm{VC}$, day of start walking after surgery, FVC, \%FVC, FEV1, and FEV1\% after surgery as the dependent variables.

SPSS software version 22.0 (IBM, Tokyo, Japan) was used to analyze the collected data, and differences were considered significant at a $p$-value $<0.05$.

\section{Results}

\subsection{Socio-Demographic and Clinical Characteristics}

A total of 41 consecutive patients ( 25 men, 16 women) were recruited. The average \pm standard deviation (SD) age at the time of the study was $66.3 \pm 9.7$ years. The average \pm SD body mass index (BMI) was $23.2 \pm 3.0 \mathrm{~kg} / \mathrm{m}^{2}$. Table 1 shows comorbidities. Some patients had multiple comorbidities.

Table 1. Comorbidities of Patient.

\begin{tabular}{cc}
\hline Comorbidities & $\mathbf{N}$ \\
\hline Chronic obstructive pulmonary disease & \\
GOLD stage I & 9 \\
GOLD stage II & 7 \\
Hypertension & 16 \\
Mitral insufficiency & 10 \\
Aortic insufficiency & 7 \\
Diabetes & 7 \\
Angina pectoris & 6 \\
Ischemic heart disease & 5 \\
Dyslipidemia & 6 \\
Tricuspid regurgitation & 2 \\
Interstitial pneumonia & 1 \\
Congestive heart failure & 1 \\
\hline
\end{tabular}

GOLD, Global Initiative for Chronic Obstructive Lung Disease.

Operative procedures were right upper lobectomy in 12 patients, right middle lobectomy in 3 patients, right lower lobectomy in 9 patients, left upper lobectomy in 9 patients, left lower lobectomy in 6 patients, and left upper and lower lobectomies in 2 patients.

The median period of preoperative rehabilitation was 3 (1-13) days. The median period of postoperative chest tube placement was $2(1-5)$ days. The patients' median day of starting walking after surgery was 2 (1-2) days. The patients' median length of stay after surgery was 8 (6-25) days. All patients achieved independent gait at 1 week after surgery. Postoperative rehabilitation was possible for 37 patients as planned. Four patients could not carry out as prescribed. Their start of aerobic exercise and stair climbing were delayed according to their conditions and took place on the POD 4, 5, 6, and 22, respectively. Postoperative complications included pneumonia in 1 patient. 


\subsection{Differences in Lung Function before and after VATS}

The average recovery rate of postoperative VC was $76.3 \% \pm 15.6 \%$. Table 2 shows lung and physical function. Postoperatively, FVC, FVC/predicted, FEV1, FEV1/FVC, and FEV1\% predicted were also decreased significantly.

Table 2. Comparisons of lung function and physical function before and after surgery for lung cancer.

\begin{tabular}{cccccc}
\hline Item & \multicolumn{2}{c}{ Preoperative } & \multicolumn{2}{c}{ Postoperative } & $p$ Value \\
\hline & Mean (SD) & Median & Mean (SD) & Median & \\
\hline FVC in L (L) & $2.5(0.6)$ & 2.4 & $1.7(0.5)$ & 1.7 & $p<0.001$ \\
FVC/pred (\%) & $88.2(15.1)$ & 87.0 & $62.2(14.8)$ & 61.0 & $p<0.001$ \\
FEV1 in L (L) & $1.9(0.5)$ & 1.9 & $1.3(0.3)$ & 1.2 & $p<0.001$ \\
FEV1/FVC (\%) & $77.6(8.7)$ & 79.6 & $76.6(8.9)$ & 78.9 & 0.367 \\
FEV1\% pred (\%) & $84.7(18.1)$ & 84.0 & $58.3(15.6)$ & 55.0 & $p<0.001$ \\
TUG (s) & $6.2(1.2)$ & 6.0 & $6.7(1.3)$ & 7.0 & 0.006 \\
CS-30 (number of times) & $16.1(4.4)$ & 16 & $15.1(4.3)$ & 14 & 0.020
\end{tabular}

FVC, forced vital capacity; pred, predicted; FEV1, forced expiratory volume in $1 \mathrm{~s}$; FEV1\%, ratio of FEV1 to FVC TUG, timed up and go test; CS-30, 30-s chair-stand test.

\subsection{Differences in Physical Function before and after VATS}

The TUG was significantly longer $(p<0.05)$, and the number of repetitions in the CS-30 was significantly less after surgery $(p<0.05)$.

\subsection{Differences in Health-Related QOL before and after VATS}

The pre- and postoperative QLQ-C30 results are shown in Table 3. After surgery, global health status/QOL scale, physical, role, social, and fatigue in the functional scales and pain, dyspnoea, sleep disturbance, appetite loss, and constipation in the symptoms scale were significantly worse compared with the preoperative evaluation $(p<0.05)$.

Table 3. Comparison of QLQ-C30 between pre- and postoperative lung cancer.

\begin{tabular}{cccccc}
\hline \multirow{2}{*}{ Item } & \multicolumn{2}{c}{ Preoperative } & \multicolumn{2}{c}{ Postoperative } & $p$-Value \\
\cline { 2 - 6 } & Mean (SD) & Median & Mean (SD) & Median \\
\hline Global health status/QOL & $68.9(20.9)$ & 667 & $58.9(20.8)$ & 50.0 & 0.003 \\
Physical function & $91.9(9.9)$ & 93.3 & $82.0(13.1)$ & 86.7 & $p<0.001$ \\
Role function & $91.5(16.3)$ & 100 & $72.9(24.7)$ & 66.7 & 0.001 \\
Emotional function & $76.0(20.3)$ & 75.0 & $78.0(20.5)$ & 75.0 & 0.455 \\
Cognitive function & $84.6(16.4)$ & 83.3 & $81.3(18.0)$ & 83.3 & 0.344 \\
Social function & $91.5(15.0)$ & 100 & $81.3(22.7)$ & 83.3 & 0.005 \\
Fatigue & $17.1(16.7)$ & 11.1 & $32.2(19.8)$ & 33.3 & 0.001 \\
Nausea/vomiting & $0.8(3.6)$ & 0 & $3.7(10.2)$ & 0 & 0.084 \\
Pain & $7.3(14.0)$ & 0 & $28.5(16.8)$ & 33.3 & $p<0.001$ \\
Dyspnea & $9.8(17.1)$ & 0 & $31.7(21.0)$ & 33.3 & $p<0.001$ \\
Insomnia/sleep & $19.5(31.6)$ & 0 & $30.9(25.2)$ & 33.3 & 0.008 \\
Appetite loss & $10.6(21.7)$ & 0 & $22.0(26.5)$ & 0 & 0.022 \\
Constipation & $13.8(22.3)$ & 0 & $22.8(30.2)$ & 0 & 0.033 \\
Diarrhea & $5.7(12.7)$ & 0 & $7.3(14.0)$ & 0 & 0.527
\end{tabular}

QOL, quality of life.

\subsection{Factors Affecting Postoperative QOL}

Table 4 shows the results of the multiple regression analyses. Stepwise multiple regression analyses showed that the presence of COPD was associated with global health status $\left(p<0.05, \mathrm{R}^{2}=0.085\right)$. The presence of COPD and the CS-30 results were associated with QOL physical $\left(p<0.05, \mathrm{R}^{2}=0.277\right)$. The FVC/predicted after surgery was associated with QOL role $\left(p<0.05, R^{2}=0.195\right)$. The recovery rate of postoperative VC was associated with QOL cognitive $\left(p<0.05, \mathrm{R}^{2}=0.148\right)$. The $\mathrm{FVC} /$ predicted after surgery was associated with QOL dyspnea $\left(p<0.05, \mathrm{R}^{2}=0.100\right)$. The results of the CS-30 were associated with appetite loss $\left(p<0.05, R^{2}=0.174\right)$. 
Table 4. Results of stepwise multiple regression analyses.

\begin{tabular}{|c|c|c|c|c|}
\hline Item & Included Variable ${ }^{\dagger}$ & $\beta$ & Adjusted $\mathrm{R}^{2}$ & $p$ Value \\
\hline $\begin{array}{l}\text { Global health } \\
\text { status/OOL }\end{array}$ & Presence or absence of COPD & -13.813 & 0.085 & 0.036 \\
\hline Physical & $\begin{array}{l}\text { Presence or absence of COPD } \\
\text { CS30 }\end{array}$ & $\begin{array}{c}-13.247 \\
1.208\end{array}$ & 0.277 & $\begin{array}{l}0.001 \\
0.007\end{array}$ \\
\hline Role & FVC/predicted after surgery & 0.769 & 0.195 & 0.003 \\
\hline Cognitive & Recovery rate of postoperative VC & -39.300 & 0.148 & 0.008 \\
\hline Dyspnea & FVC/predicted after surgery & -0.496 & 0.100 & 0.025 \\
\hline Appetite loss & CS30 & -2.703 & 0.174 & 0.004 \\
\hline Constipation & $\begin{array}{l}\text { Recovery rate of postoperative VC } \\
\text { Day of start walking after surgery }\end{array}$ & $\begin{array}{l}88.390 \\
35.801\end{array}$ & 0.269 & $\begin{array}{c}p<0.001 \\
0.010\end{array}$ \\
\hline Diarrhea & Age & 0.650 & 0.182 & 0.003 \\
\hline
\end{tabular}

$\uparrow$, Variables were selected by backward stepwise multiple regression models; QOL, quality of life; COPD, chronic obstructive pulmonary disease; CS-30, 30-s chair-stand test; FVC, forced vital capacity; VC, vital capacity; $\beta$, standardized regression coefficient.

\section{Discussion}

Our study investigated the changes in physical function, lung function, and QOL of lung cancer patients after VATS, and factors for QOL were also evaluated. The results showed that VATS had a negative short-term impact on physical function and QOL, and lung function and physical function was found to affect QOL in patients after VATS.

The percentage decreases in the VC after VATS and thoracotomy have been reported to be $68.8 \%$ [8] and $69.1 \%$ [17] at 1 week after surgery and $70.5 \%$ [8] and $69.0 \%$ [17] at two weeks after surgery. VC recovery rate of $76.3 \%$ in the present study was higher than previously reported studies, although a direct comparison is not possible because patients of this study were only VATS. VC at the time of 6 months after VATS was $88 \%$ of the preoperative value [8]. Therefore, we have thought that the patients of this study will gradually improve by 6 months after discharge.

Atelectasis following lung resection has been described as a common postoperative complication, with an incidence of $1-20 \%$ [18-21]. In the present study, the incidence of postoperative complications was only $2.0 \%$ ( 1 of 41 patients). Preoperative rehabilitation and postoperative early mobilization were emphasized in the present study because mobilization forces the patient to perform more frequent and deeper sighing respiration and promote airway clearance [22] than with respiratory exercises in bed [14]. Therefore, good results could be obtained. Furthermore, a need for long-term rehabilitation during hospitalization is suggested for patients with postoperative complications, even in VATS patients.

In the present study, the TUG and CS-30 were used to evaluate physical function and walking ability. The TUG is a clinical assessment of balance and mobility [23]. It is also a reliable tool to evaluate agility, because it involves walking and changing direction [24]. The CS-30 was used to measure lower body strength [10]. This test has been validated for measurement of lower body strength in older adults with COPD [25]. In the present study, the TUG was significantly longer, and the number of repetitions of the CS-30 was significantly lower after surgery. These results mean that patients had decreased lower limb muscular strength and balance ability postoperatively. Although patients carried out a rehabilitation program for two to 3 weeks before surgery and performed intensive early mobilization from the early postoperative period, the decline of physical performance could not be prevented. Although the invasion was minimal after VATS, we have thought that the physical function and walking ability of the patients decreased after VATS because their physical activity decreased due to pain and thoracic drain placement. As with postoperative patients with other diseases, the importance of an early increase in physical activity has been shown from the study with VATS patients [7]. This study has confirmed the previous study, and we, therefore, consider the importance of early rehabilitation.

It was previously reported that physical health-related QOL was significantly lower even six months after lung surgery compared to preoperatively [26]. However, there have been no previous studies of the short-term impact of VATS. In the present study, global 
health status, physical, role, and social, except the emotional and cognitive items of QLQC30, decreased significantly 1 week after surgery. Concerning the symptom scale, fatigue, pain, dyspnoea, insomnia, appetite loss, and constipation showed significant decreases postoperatively compared with preoperative levels. Although the reported benefits of VATS include reduced postoperative pain [27], the present findings confirmed that negative symptoms were not sufficiently improved 1 week after surgery.

As the result of examining factors affecting postoperative QOL, global health status, physical, role, cognitive, dyspnea, and appetite loss were identified on stepwise multiple regression analyses. Declining lung function, including the presence or absence of COPD, $\% \mathrm{VC}$ after surgery, and the recovery rate of postoperative $\mathrm{VC}$ may have a negative effect on global health status, physical, role, and cognitive among the items of the QLQ-C30 and dyspnea. It was suggested that postoperative QOL and lung function affected each other. Physical and appetite loss were associated with the CS-30. Patients with higher lower extremity muscle endurance might have better physical and appetite recovery.

\section{Study Limitations}

There are some limitations associated with the present study. First, the TUG and CS-30 were used to evaluate physical function, but exercise tolerance tests such as the 6-min walk distance or shuttle walking were not performed. Second, it is necessary to examine not only the short-term, but also the long-term impact of VATS longitudinally. Third, patients are limited to patients of VATS and our study cannot be compared with patients of thoracotomy. Fourth, the effect of pain on postoperative lung function and physical function has not been investigated in this study. Fifth, there was no control group without rehabilitation in the present study, which limits the conclusions about the effects of the intervention. Further research is needed to examine these issues.

\section{Conclusions}

Lung function, physical function, and QOL had not recovered sufficiently at discharge, even though preoperative and early postoperative rehabilitation was performed. However, $\mathrm{VC}$ recovery rate and the incidence of postoperative complications was better than previously reported studies, and no patients discontinued rehabilitation. Therefore, our rehabilitation program was safe and useful for patients after VATS.

Author Contributions: Conceptualization, Y.A. and E.N.; Data curation, Y.A., R.T. and O.I.; Formal analysis, Y.A.; Investigation, Y.A., R.T. and O.I.; Methodology, Y.A. and E.N.; Project administration, Y.A. and E.N.; Supervision, E.N., J.K., T.T., T.U., M.Y. and S.S.; Writing一original draft, Y.A.; Writingreview and editing, E.N., J.K., T.T., T.U., M.Y. and S.S. All authors have read and agreed to the published version of the manuscript.

Funding: This work was supported in part by the japan agency for medical research and development (AMED) practical research for innovative cancer control grant number 16ck0106215.

Institutional Review Board Statement: All procedures performed in studies involving human participants were performed under an approved protocol and in accordance with the ethical standards of shikoku cancer center ethics committee (Approval No. 113) and with the 1964 Helsinki declaration and its later amendments or comparable ethical standards.

Informed Consent Statement: Informed consent was obtained from all subjects involved in the study.

Data Availability Statement: The data presented in this study are available on request from the corresponding author. The data are not publicly available due to Participant's personal information.

Conflicts of Interest: The authors declare that they have no competing interest.

\section{References}

1. Jemal, A.; Bray, F.; Center, M.M.; Ferlay, J.; Ward, E.; Forman, D. Global cancer statistics. CA Cancer J. Clin. 2011, 61, 69-90. [CrossRef] [PubMed] 
2. Ferlay, J.; Shin, H.R.; Bray, F.; Forman, D.; Mathers, C.; Parkin, D.M. Estimates of worldwide burden of cancer in 2008: GLOBOCAN 2008. Int. J. Cancer 2010, 127, 2893-2917. [CrossRef] [PubMed]

3. Grogan, E.L.; Jones, D.R. VATS lobectomy is better than open thoracotomy: What is the evidence for short-term outcomes? Thorac. Surg Clin. 2008, 18, 249-258. [CrossRef] [PubMed]

4. Cheng, D.; Downey, R.J.; Kernstine, K.; Stanbridge, R.; Shennib, H.; Wolf, R.; Ohtsuka, T.; Schmid, R.; Waller, D.; Fernando, $\mathrm{H}$; et al. Video-assisted thoracic surgery in lung cancer resection: A meta-analysis and systematic review of controlled trials. Innovations 2007, 2, 261-292. [CrossRef]

5. Kaseda, S.; Aoki, T.; Hangai, N.; Shimizu, K. Better pulmonary function and prognosis with video-assisted thoracic surgery than with thoracotomy. Ann. Thorac. Surg. 2000, 70, 1644-1646. [CrossRef]

6. Brunelli, A.; Thomas, C.; Dinesh, P.; Lumb, A. Enhanced recovery pathway versus standard care in patients undergoing video-assisted thoracoscopic lobectomy. J. Thorac. Cardiovasc. Surg. 2017, 154, 2084-2090. [CrossRef]

7. Agostini, P.; Lugg, S.T.; Adams, K.; Smith, T.; Kalkat, M.; Rajesh, P.B.; Steyn, R.S.; Naidu, B.; Rushton, A.; Bishay, E. Video-assisted thoracoscopic lobectomy: Which patients require postoperative physiotherapy? Physiotherapy 2020, 106, 87-93. [CrossRef]

8. Nomori, H.; Ohtsuka, T.; Horio, H.; Naruke, T.; Suemasu, K. Difference in the impairment of vital capacity and 6-minute walking after a lobectomy performed by thoracoscopic surgery, an anterior limited thoracotomy, an anteroaxillary thoracotomy, and a posterolateral thoracotomy. Surg. Today 2003, 33, 7-12. [CrossRef]

9. Podsiadlo, D.; Richardson, S. The timed "Up \& Go": A test of basic functional mobility for frail elderly persons. J. Am. Geriatr. Soc. 1991, 39, 142-148.

10. Jones, C.J.; Rikli, R.E.; Beam, W.C. A 30-s chair-stand test as a measure of lower body strength in community-residing older adults. Res. Q Exerc. Sport. 1999, 70, 113-119. [CrossRef]

11. Aaronson, N.K.; Ahmedzai, S.; Bergman, B.; Bullinger, M.; Cull, A.; Duez, N.J.; Filiberti, A.; Flechtner, H.; Fleishman, S.B.; de Haes, J.C.; et al. The European Organization for Research and Treatment of Cancer QLQ-C30: A quality-of-life instrument for use in international clinical trials in oncology. J. Natl. Cancer Inst. 1993, 85, 365-376. [CrossRef] [PubMed]

12. Kubota, M.; Kobayashi, H.; Quanjer, P.H.; Omori, H.; Tatsumi, K.; Kanazawa, M. Reference values for spirometry, including vital capacity, in Japanese adults calculated with the LMS method and compared with previous values. Respir. Investig. 2014, 52, 242-250. [CrossRef]

13. Sawabata, N.; Nagayasu, T.; Kadota, Y.; Goto, T.; Horio, H.; Mori, T.; Yamashita, S.; Iwasaki, A. Risk assessment of lung resection for lung cancer according to pulmonary function: Republication of systematic review and proposals by guideline committee of the Japanese association for chest surgery 2014. Gen. Thorac. Cardiovasc. Surg. 2015, 63, 14-21. [CrossRef] [PubMed]

14. Montazeri, A.; Gillis, C.R.; McEwen, J. Quality of life in patients with lung cancer: A review of literature from 1970 to 1995. Chest 1998, 113, 467-481. [PubMed]

15. Abendstein, H.; Nordgren, M.; Boysen, M.; Jannert, M.; Silander, E.; Ahlner-Elmqvist, M.; Hammerlid, E.; Bjordal, K. Quality of life and head and neck cancer: A 5 year prospective study. Laryngoscope 2005, 115, 2183-2192. [CrossRef]

16. Bjordal, K.; de Graeff, A.; Fayers, P.M.; Hammerlid, E.; van Pottelsberghe, C.; Curran, D.; Ahlner-Elmqvist, M.; Maher, E.J.; Meyza, J.W.; Brédart, A.; et al. A 12 country field study of the EORTC QLQ-C30 (version 3.0) and the head and neck cancer specific module (EORTC QLQ-H\&N35) in head and neck patients. EORTC Qual. Life Group. Eur. J. Cancer. 2000, 36, $1796-1807$.

17. Nomori, H.; Horio, H.; Naruke, T.; Suemasu, K. What is the advantage of a thoracoscopic lobectomy over a limited thoracotomy procedure for lung cancer surgery? Ann. Thorac. Surg. 2001, 72, 879-884. [CrossRef]

18. Stéphan, F.; Boucheseiche, S.; Hollande, J.; Flahault, A.; Cheffi, A.; Bazelly, B.; Bonnet, F. Pulmonary complications following lung resection: A comprehensive analysis of incidence and possible risk factors. Chest 2000, 118, 1263-1270.

19. Uramoto, H.; Nakanishi, R.; Fujino, Y.; Imoto, H.; Takenoyama, M.; Yoshimatsu, T.; Oyama, T.; Osaki, T.; Yasumoto, K. Prediction of pulmonary complications after a lobectomy in patients with non-small cell lung cancer. Thorax 2001, 56, 59-61. [CrossRef]

20. Uzieblo, M.; Welsh, R.; Pursel, S.E.; Chmielewski, G.W. Incidence and significance of lobar atelectasis in thoracic surgical patients. Am. Surg. 2000, 66, 476-480.

21. Korst, R.J.; Humphrey, C.B. Complete lobar collapse following pulmonary lobectomy. Its incidence, predisposing factors, and clinical ramifications. Chest 1997, 111, 1285-1289. [CrossRef] [PubMed]

22. Abolhoda, A.; Liu, D.; Brooks, A.; Burt, M. Prolonged air leak following radical upper lobectomy: An analysis of incidence and possible risk factors. Chest 1998, 113, 1507-1510. [CrossRef] [PubMed]

23. Donoghue, O.A.; Horgan, N.F.; Savva, G.M.; Cronin, H.; O’Regan, C.; Kenny, R.A. Association between timed up-and-go and memory, executive function, and processing speed. J. Am. Geriatr. Soc. 2012, 60, 1681-1686. [CrossRef] [PubMed]

24. Hollands, K.L.; Hollands, M.A.; Zietz, D.; Wing, A.M.; Wright, C.; van Vliet, P. Kinematics of turning $180^{\circ}$ during the timed up and go in stroke survivors with and without falls history. Neurorehabil. Neural Repair. 2010, 24, 358-367. [CrossRef] [PubMed]

25. Benton, M.J.; Alexander, J.L. Validation of functional fitness tests as surrogates for strength measurement in frail, older adults with chronic obstructive pulmonary disease. Am. J. Phys Med. Rehabil. 2009, 88, 579-583. [CrossRef]

26. Demmy, T.L.; Nwogu, C. Is video-assisted thoracic surgery lobectomy better? Quality of life considerations. Ann. Thorac. Surg. 2008, 85, S719-S728. [CrossRef]

27. Puri, V.; Meyers, B.F. Video-assisted thoracoscopic surgery lobectomy for lung cancer. Surg. Oncol. Clin. N. Am. 2013, 22, 27-38. [CrossRef] 